\title{
POTENTIAL IMPACT OF MARJORAM ON CORAGEN-INDUCED PHYSIOLOGICAL AND HISTOLOGICAL ALTERATIONS IN MALE ALBINO RATS
}

\author{
Hanaa Fawzy Hassan; Honyda S. Mohammed; Noha M. Meligi*
}

Zoology Department, Faculty of Science, Minia University, Minia, Egypt

\begin{abstract}
Article History:

Received: 9 November 2020

Accepted: 29 December 2020

Published Online:

3 January 2021

Keywords:

Anemia

Coragen toxicity

Hormonal assay

Kidney dysfunction

Origanum majorana

*Correspondence:

Noha Meligi

Zoology Department

Faculty of Science

Minia University

Minia, Egypt

E-mail:

noha.melege@mu.edu.eg

Insect control has been accomplished by insecticides many years ago. Such insecticides can be useful in dealing with insects in our environment; but when they are used wrongly, they have hazards to the environment too. The current study continues to evaluate the potential alleviative effects of marjoram (Origanum majorana L.) on coragen-induced alterations in hematological and hormonal parameters, as well as renal and testicular structure, in male albino rats. Thirty adult male albino rats (Sprague-Dawely) were randomly separated into 3 groups $(n=10)$. The first group received orally $1.0 \mathrm{~mL}$ distilled water only; the second group was treated orally with a sublethal dose of coragen suspension $(2 \mathrm{~g} / \mathrm{kg}$ body weight in $1.0 \mathrm{~mL}$ distilled water); and the third one was treated orally with coragen suspension $(2 \mathrm{~g} / \mathrm{kg}$ body weight in $1.0 \mathrm{~mL}$ distilled water) and marjoram suspension $(5 \mathrm{~g} / \mathrm{kg}$ body weight in $1.0 \mathrm{~mL}$ distilled water) together, three times a week for 30 days. The results revealed that marjoram alleviated significantly $(P<0.05)$ coragen-induced microcytic anemia, leukocytosis, thrombocythemia, hyperuricemia, kidney dysfunction, alterations in plasma hormones (sex and thyroid hormones, as well as aldosterone levels), and histological changes in kidneys and testes of male rats. In conclusion, marjoram showed a notable effect against the toxicity of coragen in male rats.
\end{abstract}

\section{INTRODUCTION}

Excessive use of pesticides for many purposes, such as agriculture and public health, has resulted in adverse health and environmental complications for both humans and animals ${ }^{[1]}$. Pesticides enhance the production of reactive oxygen species (ROS) that sequentially cause oxidative stress in different tissues. Usually high oxidative stress reduces the action of the antioxidant defense system and sequentially promotes the generation of free radicals that, in turn, may react with fatty acids (polyunsaturated) leading to lipid peroxidation ${ }^{[1]}$. Coragen is an anthranilic diamide insecticide containing the active ingredient chlorantraniliprole $\left(\mathrm{C}_{18} \mathrm{H}_{14} \mathrm{BrCl}_{2} \mathrm{~N}_{5} \mathrm{O}_{2}\right)$; it is used against a broad range of lepidopteran pests, such as boll-worms and fruit-worms, but induced broad side effects on hematological and biochemical parameters in mammals such as rats ${ }^{[2,3]}$. Kidneys are dynamic organs that maintain the body's homeostasis. Commonly, 
many drugs and chemical compounds can affect their functions ${ }^{[4,5]}$. Kidney disease may be related to pesticide exposure. Although the mechanism of how pesticides affect kidney function has yet to be clarified, researchers believe that the accumulated amount of pesticides leads to renal failure by inducing oxidative stress in the kidneys ${ }^{[5]}$. Exposure to insecticides, such as abamectin, has led to alterations in reproductive and endocrine systems in both experimental and wildlife ${ }^{[6]}$. In addition, abamectin can be quantified in human reproductive fluids, including semen and ovarian follicular fluid, causing male infertility, testicular dysfunction, abortion, neonatal death, and congenital defects ${ }^{[6]}$. Abamectin also disrupt the functions of the thyroid gland and affect the circulating balance of the thyroid hormones ${ }^{[6]}$.

The use of natural antioxidants such as herbal and natural products for curing pesticides-induced hematological changes $^{[3]}$ and renal toxicity/injury ${ }^{[7]}$ has been extensively studied. Sweet marjoram (Origanum majorana L.), family Lamiaceae, is well known to be an herbaceous and perennial plant popular in southern Europe, north Africa, and southwest Asia that have strong antioxidant activity ${ }^{\left[{ }^{[-11]}\right.}$. In traditional remedy, marjoram is used for cramps, vertigo, gastrointestinal illnesses, depression, nervous headache, spasmodic coughs, and as a diuretic and to promote menstruation ${ }^{[9]}$. Furthermore, natural antioxidants of marjoram leaves and their extracts are generally documented as safe and effective in preventing lipid peroxidation/cellular injury $^{[9-11]}$. Marjoram showed some pharmacological influences including hepatoprotective, cardioprotective, and immunostimulating activities ${ }^{[9-12]}$. Recently, we explored some protective effects of marjoram against coragen-induced liver injury and dyslipidemia, as well as histopathological changes of spleen and lungs, in male albino rats ${ }^{[13]}$. The current study continues to evaluate the potential alleviative effects of marjoram on corageninduced alterations in hematological and hormonal parameters, as well as renal and testicular structure, in male albino rats.

\section{MATERIAL AND METHODS Experimental animals}

Thirty healthy adult male albino rats (Sprague-Dawley) aged 6-8 weeks, weighing 150-200 g, were obtained from the Dokki Research Laboratory in Egypt. Experimental rats were given access to a daily diet and water ad libitum. The rats were left for 2 weeks, as acclimatization time, in plastic cages in a well-ventilated space before the start of the experiments.

\section{Tested pesticide}

Coragen 20 SC (20\% chlorantraniliprole) was obtained from Agrimatco (Giza, Egypt). The dosage of coragen $(2 \mathrm{~g} / \mathrm{kg}$ body in $1.0 \mathrm{~mL}$ distilled water) was administered orally, three times a week for 30 days, using a stainless-steal stomach tube.

\section{Plant material preparation}

Marjoram (dried leaves) was bought at a nearby Egyptian market. First, the dried leaves of the plant ( $5 \mathrm{~g} / \mathrm{kg}$ body weight) were squashed and then suspended in $1.0 \mathrm{~mL}$ distilled water just before using.

\section{Experimental design}

Thirty rats were randomly separated into three groups $(\mathrm{n}=10$ each). The first group (normal control rats) administered orally $1.0 \mathrm{~mL}$ of distilled water three times a week for 30 days. The second group (coragentreated rats) administered orally $2 \mathrm{~g} / \mathrm{kg}$ body weight of coragen suspension in $1.0 \mathrm{~mL}$ distilled water three times a week for 30 days $^{[13]}$. The third group (coragen +marjoram-treated rats) administered orally a mixture of coragen suspension $(2 \mathrm{~g} / \mathrm{kg}$ body weight in $1.0 \mathrm{~mL}$ distilled water) and marjoram suspension $(5 \mathrm{~g} / \mathrm{kg}$ body weight in $1.0 \mathrm{~mL}$ distilled water) three times a week for 30 days orally ${ }^{[13]}$.

\section{Sampling of blood}

After 30 days of treatment, all animals were fasted overnight and then killed through cervical decapitation, after which blood samples are taken. Samples of whole 
blood were immediately obtained for hematological analysis using anticoagulant "EDTA". Both plasma and serum samples were prepared from anticoagulated and coagulated blood, respectively, and kept at $-80^{\circ} \mathrm{C}$ for subsequent biochemical study.

\section{Estimation of hematological parameters}

By using automated hematology analyzer (Celltac Alpha MEK-6510, Nihon Kohden, Tokyo, Japan) the hematological parameters were evaluated in the present study such as: red blood corpuscles (RBC), while blood cells (WBC), and platelets counts, hemoglobin $(\mathrm{Hb})$ content, hematocrit (Hct) value, and mean corpuscular volume (MCV).

\section{Estimation of biochemical analysis}

Serum uric acid, urea, and creatinine concentrations were calorimetrically determined using commercial kits from ERBA Diagnostics Mannheim Gmbh (London, UK), Spectrum Diagnostics (Cairo, Egypt), and Diamond Diagnostics (Budapest, Hungary), respectively. Plasma total and free testosterone, progesterone, and estradiol concentrations were assayed by a competitive chemiluminescent enzyme immunoassay ${ }^{[14-16]}$. Plasma tri-iodothyronine (T3), thyroxine (T4), and thyroid stimulating hormone (TSH) concentrations were estimated using a chemiluminescent microparticle immunoassay ${ }^{[17-19]}$. Plasma aldosterone concentration was estimated using an enzyme-linked immunosorbent assay ${ }^{[20]}$.

\section{Histological sections preparation}

The kidney and the testis samples were isolated and fixed in $10 \%$ formal saline for a day, handled through a graded ethanol series, and embedded in paraffin. Then the paraffin sections were cut into slices (5 microns thick) and stained with hematoxylin $(\mathrm{H})$ and eosin (E) for light microscopy examination.

\section{Statistical analysis}

Data were analyzed using statistical package of social sciences (SPSS) statistics software for windows, Version 22 (IBM corp., Armonk, NY, USA). The significance was calculated via one-way analysis of variance (ANOVA), followed by Tukey's multiple comparison procedure. The results were stated as the mean \pm standard deviation, and $P<0.05$ was considered as the level of significance.

\section{RESULTS}

Marjoram alleviated the changes in hematological parameters in the coragenintoxicated male rats

There was a significant decrease in hemoglobin content, hematocrit value, and MCV after coragen administration in comparison to the control group $(P<0.05$, Table 1). Nevertheless, no statistical alterations were detected in RBC counts in the coragen-treated group compared to the control group. On the other hand, WBC and platelet counts were increased significantly $(P<0.05)$ in the coragen-treated group compared to the control group. Marjoram reverted all changes in the hematological parameters in coragen-treated rats to near the control values, except for WBC counts, which was still significantly higher in the coragen+marjoram-treated group in comparison with the control group $(P<0.05$, Table 1$)$.

Marjoram alleviated the disturbance in kidney functions in the coragenintoxicated male rats

Uric acid, urea, and creatinine levels exhibited a significant increase in response to the insecticide when compared to the control group $(P<0.05$, Table 2$)$. Marjoram modulated significantly $(P<0.05)$ all changes in uric acid, urea, and creatinine levels in coragen-treated rats. Uric acid and creatinine levels were still significantly higher in the coragen+marjoram-treated group in comparison with the control group $(P<0.05$, Table 2).

Marjoram alleviated alterations in plasma hormonal levels in the coragenintoxicated male rats

Plasma total and free testosterone levels were significantly decreased in the coragentreated group versus the control group 
Table 1: Effects of marjoram on some hematological parameters in coragen-treated male albino rats.

\begin{tabular}{lccc}
\hline & Control & Coragen & Coragen+Marjoram \\
\cline { 2 - 4 } RBCs $\left(10^{6} / \mathrm{mm}^{3}\right)$ & $8.70 \pm 0.52$ & $6.61 \pm 0.33$ & $7.66 \pm 0.44$ \\
$\mathrm{Hb}(\mathrm{g} / \mathrm{dL})$ & $13.12 \pm 0.57$ & $10.79 \pm 0.78^{\mathrm{a}}$ & $12.67 \pm 0.40^{\mathrm{b}}$ \\
$\mathrm{Hct}(\%)$ & $38.32 \pm .49$ & $34.76 \pm 0.72^{\mathrm{a}}$ & $38.11 \pm 0.98^{\mathrm{b}}$ \\
MCV $(\mathrm{fL})$ & $49.78 \pm 3.85$ & $45.05 \pm 1.43^{\mathrm{a}}$ & $50.90 \pm 1.79^{\mathrm{b}}$ \\
WBC $\left(10^{3} / \mathrm{mm}^{3}\right)$ & $8.45 \pm 0.63$ & $13.70 \pm 0.93^{\mathrm{a}}$ & $10.33 \pm 0.90^{\mathrm{a}, \mathrm{b}}$ \\
Platelets $\left(10^{3} / \mathrm{mm}^{3}\right)$ & $372.11 \pm 22.77$ & $615.70 \pm 43.95^{\mathrm{a}}$ & $461.20 \pm 41.11^{\mathrm{b}}$ \\
\hline
\end{tabular}

Data were expressed as mean \pm standard deviation $(n=6)$. RBCs: red blood cells, $\mathrm{Hb}$ : hemoglobin, Hct: hematocrit, MCV: mean corpuscular volume (MCV), WBCs: white blood cells. ${ }^{\mathrm{a}} P<0.05$ : significant difference versus the control group, ${ }^{\mathrm{b}} P<0.05$ : significant difference of coragen+marjoram-treated group versus coragen-treated group.

Table 2: Effects of marjoram on serum uric acid $(\mathrm{mg} / \mathrm{dL})$, urea $(\mathrm{mg} / \mathrm{dL})$, and creatinine $(\mathrm{mg} / \mathrm{dL})$ in coragen-treated male albino rats.

\begin{tabular}{lrcc}
\hline & \multicolumn{1}{l}{ Control } & \multicolumn{1}{l}{ Coragen } & Coragen+Marjoram \\
\cline { 2 - 4 } Uric acid (mg/dL) & $2.17 \pm 0.31$ & $5.72 \pm 0.29^{\mathrm{a}}$ & $3.60 \pm 0.83^{\mathrm{a}, \mathrm{b}}$ \\
Urea $(\mathrm{mg} / \mathrm{dL})$ & $33.40 \pm 4.16$ & $43.60 \pm 3.94^{\mathrm{a}}$ & $37.20 \pm 3.08^{\mathrm{b}}$ \\
Creatinine $(\mathrm{mg} / \mathrm{dL})$ & $1.03 \pm 0.13$ & $1.69 \pm 0.14^{\mathrm{a}}$ & $1.26 \pm 0.29^{\mathrm{a}, \mathrm{b}}$ \\
\hline
\end{tabular}

Data were expressed as mean \pm standard deviation $(\mathrm{n}=6)$. ${ }^{\mathrm{a}} P<0.05$ : significant difference versus the control group, ${ }^{\mathrm{b}} P<0.05$ : significant difference of coragen+marjoram-treated group versus coragen-treated group.

$(P<0.05$, Table 3$)$. However, there was an insignificant change $(P>0.05)$ in the plasma progesterone level after coragen exposure. In addition, the plasma estradiol level exhibited a significant increase in the coragen-exposed group compared to the control group $(P<0.05)$. Marjoram modulated significantly $(P<0.05)$ all changes in plasma sex hormones levels in the coragen-treated rats, but they were still significantly different $(P<0.05)$ from that in the control values (Table 3 ).

Plasma T3, T4, and TSH levels were significantly affected $(P<0.05)$ in the coragen-treated rats compared to the control group (Table 3). Marjoram modulated significantly $(P<0.05)$ all changes in plasma thyroid hormones levels in coragen-treated rats and reverted the values to the control values, except for T3 level, which was still significantly lower in the coragen+marjoram-treated group in comparison with the control group $(P<0.05$, Table 3).

In addition, the plasma aldosterone level increased significantly $(P<0.05)$ in the group treated with coragen compared to the control group (Table 3). However, a significant decrease/increase $(P<0.05)$ was distinguished in plasma aldosterone level in coragen+marjoram-treated groups in comparison with the coragen-treated group and the control group, respectively $(P<0.05$, Table 3$)$. 
Table 3: Effects of marjoram on plasma hormone levels in coragen-treated male albino rats.

\begin{tabular}{lrcc}
\hline & \multicolumn{1}{l}{ Control } & \multicolumn{1}{l}{ Coragen } & Coragen+Marjoram \\
\cline { 2 - 4 } Testosterone $(\mathrm{ng} / \mathrm{mL})$ & $3.78 \pm 0.07$ & $0.81 \pm 0.058^{\mathrm{a}}$ & $2.79 \pm 0.21^{\mathrm{a}, \mathrm{b}}$ \\
Free testosterone $(\mathrm{ng} / \mathrm{mL})$ & $6.33 \pm 0.10$ & $2.40 \pm 0.17^{\mathrm{a}}$ & $5.16 \pm 0.60^{\mathrm{a}, \mathrm{b}}$ \\
Progesterone $(\mathrm{ng} / \mathrm{mL})$ & $1.12 \pm 0.39$ & $1.69 \pm 0.12$ & $1.45 \pm 0.17$ \\
Estradiol $(\mathrm{pg} / \mathrm{mL})$ & $17.00 \pm 0.58$ & $21.40 \pm 0.84^{\mathrm{a}}$ & $18.50 \pm 0.84^{\mathrm{a}, \mathrm{b}}$ \\
Tri-iodothyronine $(\mathrm{ng} / \mathrm{mL})$ & $49.57 \pm 0.45$ & $46.70 \pm 0.67^{\mathrm{a}}$ & $48.20 \pm 0.42^{\mathrm{a}, \mathrm{b}}$ \\
Thyroxine $(\mathrm{ng} / \mathrm{mL})$ & $3.83 \pm 0.08$ & $2.66 \pm 0.29^{\mathrm{a}}$ & $3.76 \pm 0.17^{\mathrm{b}}$ \\
TSH (ng/mL) & $0.98 \pm 0.52$ & $3.00 \pm 0.21^{\mathrm{a}}$ & $2.10 \pm 0.13^{\mathrm{b}}$ \\
Aldosterone $(\mathrm{ng} / \mathrm{dL})$ & $131.40 \pm 0.69$ & $223.59 \pm 10.57^{\mathrm{a}}$ & $150.10 \pm 4.9^{\mathrm{a}, \mathrm{b}}$ \\
\hline
\end{tabular}

Data were expressed as mean \pm standard deviation $(\mathrm{n}=6)$. TSH: thyroid stimulating hormone ${ }^{\mathrm{a}} P<0.05$ : significant difference versus the control group, ${ }^{\mathrm{b}} P<0.05$ : significant difference of coragen+marjoram-treated group versus coragen-treated group.

Marjoram alleviated histological alterations in the kidneys and testes of the coragen-intoxicated male rats

Examination of histological sections of the kidneys of the control group revealed normal structure of the renal glomeruli with normal Bowman's capsule and distinct urinary space; the proximal tubules and the distal convoluted tubules also showed normal structure (Figure 1a). Histological examination of the kidneys of the coragen-treated group showed marked changes such as a few shrunken glomeruli, thus more spaces appeared between Bowman's capsule and glomeruli, as well as few glomeruli with vacuolated cells; the renal tubules showed degenerative changes and appeared more elongated with low cuboidal epithelium; increased vascularity was seen in the form of dilated and congested blood vessels engorged with blood; there were also several foci of inflammatory cells between the tubules, suggestive of interstitial nephritis, and necrosis in some areas (Figures 1b and c). In the coragen+marjoram-treated group the histological structure of the kidneys were improved, whereas the distal and the proximal tubules returned to normal appearance; glomerulus also returned to normal size with normal urinary space and arranged Bowman's capsule, except there were some vacuolation in cells of glomerulus and a few inflammatory cells between tubules (Figure 1d).

Histological structure of testes from the control group showed normal structural organization of the seminiferous tubules, normal spermatogenic cells, and normal interstitial tissue with normal Leydig cells appearance (Figures 2a and b). The testes of the coragen-treated group showed disturbances in the normal architecture such as irregularity of some of the seminiferous tubules, which were widely separated from each other and the basement membrane was focally separated from the overlying germinal epithelium; widening of the interstitium with deposition of vacuolated acidophilic material and dilated congested blood vessels; some spermatogenic cells appeared disorganized with wide intercellular spaces and others with deeply stained nuclei; absence of spermatozoa in the lumen of some tubules; and many spermatogonia revealed deeply stained nuclei (Figures $2 \mathrm{c}$ and d). On the other hand, the testes of the coragen+marjoram-treated group revealed signs of improvement, where the seminiferous tubules appeared with almost regular distribution of spermatogenic 
cells and increased number of sperms compared with that of coragen-treated group; but slight edema still present between the tubules, as well as some deeply stained nuclei of spermatogonia (Figures 2e and f).
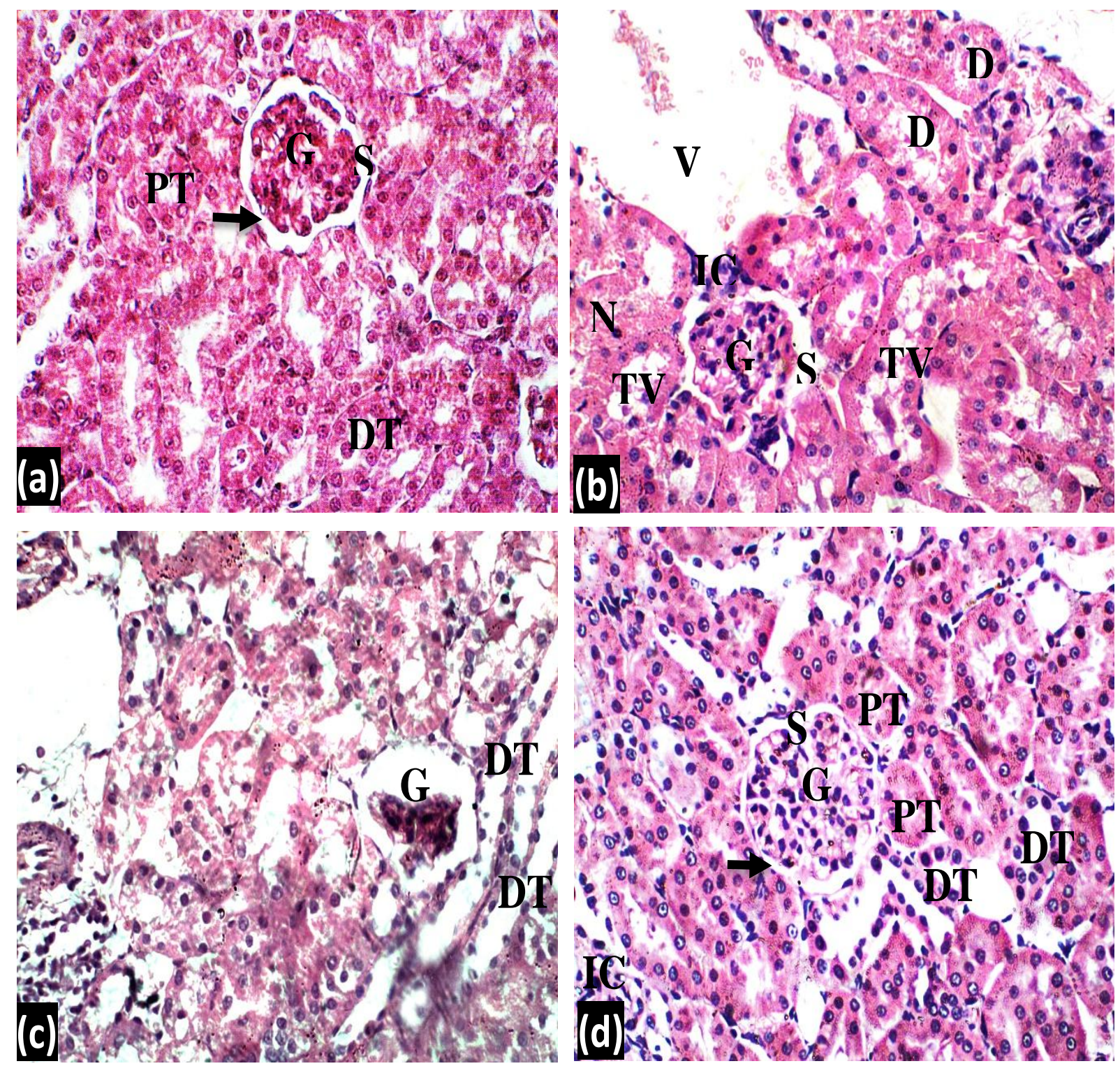

Figure 1: Photomicrographs of sections of rat kidney stained with hematoxylin and eosin $(\times 400)$ : (a) control group showing normal structure of renal glomeruli $(\mathrm{G})$, bowman's capsule lined by squamous epithelium (arrow), distinct urinary space (S), the proximal tubules (PT) are lined with cubiodal epithelium, and distal convoluted tubules (DT) are lined with low cuboidal epithelium; (b) coragen-treated group showing vaculation in cells of glomerulus (G) and in tubules (TV), increased urinary space (S), dilated blood vessel (V), degenerated tubules (D), necrosis in some areas (N) and aggregation of inflammatory cells between tubules (IC); (c) coragen-treated group, showing shrunken glomerulus (G) and elongated distal tubules with low cuboidal epithelium (DT); (d) coragen+marjoram-treated group showing improvement in architecture of kidney tissue, where glomerulus (G) return to normal size with normal urinary space (S) and arranged Bowman's capsule (arrow), as well as normal distal tubules (DT) and proximal (PT), except there were some vaculation in cells of glomerulus and few inflammatory cells between tubules (IC). 


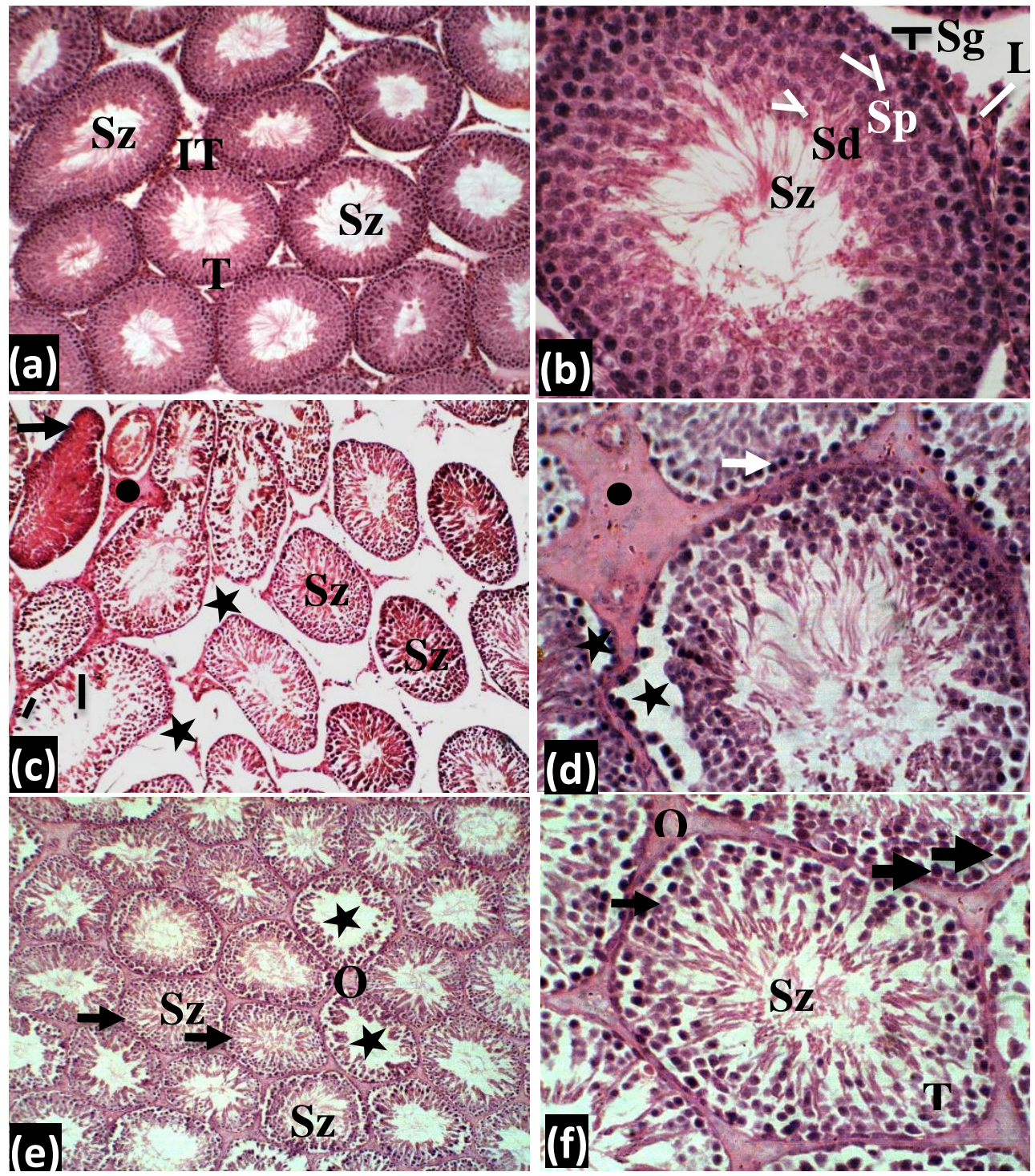

Figure 2: Photomicrographs of sections of rat testis stained with hematoxylin and eosin (a, c, and e: $\times 100$; b, d, and $\mathrm{f}: \times 100)$ : (a) control group showing rounded to oval seminiferous tubules $(\mathrm{T})$ with normal spermatogenic cells and spermatozoa $(\mathrm{Sz})$, in between there is the interstitial tissue (IT); (b) control group showing parts of adjacent seminiferous tubules lined by normal spermatogenic cells: spermatogonia $(\mathrm{Sg})$, primary spermatocytes $(\mathrm{Sp})$, spermatids $(\mathrm{Sd})$, and spermatozoa $(\mathrm{Sz})$. The interstitial tissues between the tubules contained Leydig cells (L); (c) coragen-treated group showing irregular seminiferous tubules with spermatozoa (Sz) in some of them and wide intercellular spaces (lines), dilated congested blood vessel (arrow), and wide interstitium (star). There is also acidophilic material (circle) and disorganization of spermatogenic cells with no spermatozoa in the lumen; (d) coragen-treated group showing deeply stained nuclei of spermatogonia (arrow), detached cells from the basal layer (star), and vacuolated acidophilic material (circle); (e) coragen+marjoram-treated group showing signs of improvement in the form of increased spermatogenic cell layer (arrow) with increased spermatozoa bundles in the lumen (Sz). Some tubules are still affected (star) and slight edema between tubules $(\mathrm{O})$; (f) coragen+marjoram-treated group showing adjacent seminiferous tubules with signs of regeneration, where the seminiferous tubules $(\mathrm{T})$ appeared with almost regular distribution of spermatogenic cells (thin arrow) and increased number of spermatozoa $(\mathrm{Sz})$, but slight edema present between tubules $(\mathrm{O})$, and some deeply stained nuclei of spermatogonia still present (thick arrows). 


\section{DISCUSSION}

In the present study, a decrease in $\mathrm{Hb}$ content, Hct value and MCV values is indicative of microcytic anemia. Other studies also reported anemia in rodents treated with various pesticides such as dichlorvos and abamectin ${ }^{[21,22]}$. They suggested that the resulted anemia may be related to the excessive destruction of red blood cells beyond the bone marrow production capacity and the decline in the body iron content ${ }^{[21,22]}$. In the current study the RBCs count was not significantly affected, however the Hct value and MCV were significantly decreased, indicating that the problem was due to the decrease in the size of RBCs, and hence their capacity to carry $\mathrm{Hb}$. In addition, thrombocytosis and leukocytosis have also been found in coragen-treated group. In contrast to our results, Kumar et al ${ }^{[2]}$ reported that coragen decreased significantly the WBCs count, as a result of problems in the development of the stem cells. In our study, leukocytosis might be attributable to inflammation-tissue necrosis. In addition, a stimulation of the immune defense mechanism of the animal may be suggested.

Uric acid, urea, and creatinine are protein catabolism waste products that need to be excreted by the kidney ${ }^{[7]}$. Therefore, the significant increase in serum levels of such parameters as noticed after coragen administration in the present study, confirmed a disturbance in kidney functions. Dutta et $a l^{[3]}$ suggested that the kidney dysfunction of coragen-treated rats could possibly arise as a consequence of oxidative stress.

Earlier studies have exhibited that some insecticides were capable of inducing functional changes and hormonal variations in the sexual organs ${ }^{[23]}$. Administration of a sublethal dose of coragen adversely affected the reproductive function of male rats by a significant decrease in total and free plasma testosterone levels. Fattahi et al. ${ }^{[23]}$ also showed that some insecticides such as diazinon reduced the levels of total and free testosterone in male mice, which may be attributable to a direct impairment of insecticide on leydig cells which encompass approximately $17 \%$ of the interstitial tissue in rats besides they are considered to be the main place of testicular androgen. Meanwhile, our findings showed an elevation of the progesterone and estradiol levels in coragentreated rats. This elevation of these steroids hormones could be ascribed to the occurrence of vacuolation along with the hypertrophy of the adrenal cortex that increased the steroidogenic activity ${ }^{[24]}$. Some insecticides, such as dicofol, showed a direct effect on the testes or, in other way, on the hypothalmo-hypophyseal testicular $\operatorname{axis}^{[24]}$. Furthermore, the estrogenic activity may be formed as dicofol raise the estradiol level through binding to estrogen receptors or by a direct effect on sertoli cells, then decreased 3-hydroxy-steroiddehydrogenase activity to decrease the conversion of estradiol to androgen ${ }^{[24]}$.

A wide range of insecticides have been linked to the thyroid hormones disturbance in rats. These insecticides alter the levels of thyroid hormones through affecting the thyroid gland, otherwise through an elevation of peripheral elimination of thyroid hormones ${ }^{[25]}$. Coragen-exposed rats had significant lower plasma T3 and T4 levels, as well as a significantly higher plasma TSH level when compared to control group. El-Kashoury et $a l .^{[24]}$ suggested that lower T4 level may be attributed to hypothyroidism, subsequently the thyroid gland failed to manufacture the T4 because of the iodine deficiency, as well as increased rate of $\mathrm{T} 4$ removal from the blood due to increased deiodination and the biliary excretion of the T4 by insecticides. Abou El-Magd et al. ${ }^{[26]}$ mentioned in their work that the activity of hepatic type 1 iodothyronin 5'-monodeiodinase was decreased, thus converting of $\mathrm{T} 4$ to the more effective T3 was also decreased with an increase in TSH level. Moreover, the high TSH level attributed to an increase in hepatic 
microsomal thyroxine uridine 5'-diphosphoglucuronosyltransferase activity, which led to increase glucuronidation and elimination of the $\mathrm{T} 4^{[27]}$.

Generally, an aldosterone plays an essential part in the adjustment of blood pressure and the stability of electrolytes and fluids in the blood ${ }^{[28]}$. Our present study showed a significant increase in the plasma aldosterone level of coragen-treated rats compared to the control group. Meligi and Hassan $^{[29]}$ indicated that some insecticides such as abamectin increased the aldosterone level (hyperaldosteronism) in male rats, which may be due to hyperactivity in an adrenal gland. In addition, there are several health problems including hypertension and low levels of potassium in the blood due to hyperaldosteronism ${ }^{[29]}$.

In the current study, rats treated with coragen showed histopathological changes in the kidneys. The detected changes were reduction in the glomeruli size, accompanied by a widening of the urinary spaces. The same results were observed by Rekha et al. ${ }^{[30]}$ in chlorpyrifos-exposed experimental animals. Decreased the glomeruli size may have been due to nephron-toxicant that leads to renal vasoconstriction. Moreover, since the renal tubules are the most common site of the renal toxicity; it is well known that xenobiotics have the ability to selectively accumulate in the renal tubules. After the xenobiotics administration, the separation of damaged cells from the basement membrane of the tubules may be due to the toxicant effect, which has induced changes in the membrane solidity, ATP depletion, and cytoskeleton component ${ }^{[30]}$. Furthermore, tubular degeneration, tubular vacuolization, and necrosis were noticed in the current study in coragen-treated animals. These changes may have resulted from the functional disorders caused by the toxicants on the renal cell that made them unable to transport ion pumps ${ }^{[30]}$. Also, our results revealed that administration of coragen caused leakage of lymphocytes in the renal interstitial space of rats. This leakage of such an inflammatory cell type may be due to hypersensitivity of interstitial nephritis following administration of a toxic drug ${ }^{[30]}$. We also noticed that blood vessels have been dilated, and this may be an attempt to detoxify the blood.

Our current study showed histopathological changes in the testes of coragen-treated rats such as irregular seminiferous tubules, wide intercellular spaces, dilated congested blood vessels, and wide interstitium. There were also acidophilic material and disorganization of the spermatogenic cells with no spermatozoa in the lumen, deeply stained nuclei of spermatogonia, and detached cells from the basal layer in coragen-treated animals. In addition, Debnath and Mandal ${ }^{[31]}$ reported similar changes by exposing rats to organochlorine chlordane, which caused disturbance in the testicular tissues and decreased the size of seminiferous tubules. In addition, Sheweita et al. ${ }^{[32]}$ and Nose ${ }^{[33]}$ reported that over-production of oxidizing substances such as ROS may result in apoptosis or necrosis. As proposed by Latchoumycandane and Mathur ${ }^{[34]}$, oxidative stress may represent a specific mechanism for certain testicular cells in endocrine disruptor-mediated dysfunction. Furthermore, Babazade and Najafi ${ }^{[35]}$ reported that the toxicity of different insecticides like chlorpyrifos may lead to the inhibition of production of mitochondrial ATP during the uncoupling of oxidative phosphorylation resulting in production of ROS that lead to tissue destruction and oxidative stress. They reported that sperms are the site of manufacturing ROS; random production of ROS produced distortions of sperms, decay of spermatogenic cells, and sterility ${ }^{[35]}$. They also reported that insecticides showed decomposition effects that may reduce the epithelium thickness of the seminiferous tubules $^{[35]}$.

To a much greater extent, the hematological indices, kidney functions, and testicular structure of coragen-treated animals were improved by marjoram. This therapeutic role of marjoram regarding the 
hematological parameters may be related to their phytochemical components that led to an increase in the $\mathrm{Hb}$ synthesis, as seen in the current study. Shati ${ }^{[36]}$ reported that the administration of the aqueous extract of marjoram improved kidney functions in cadmium-treated rats. He suggested that the water extract of marjoram had a therapeutic and chelating effect against cadmiuminduced nephrotoxicity ${ }^{[36]}$. Previous study indicated that marjoram essential oils had a considerable free radical scavenging activity, thus protecting the organs of the body from injury associated with dietary obesity ${ }^{[37]}$. The synthetic compounds or drugs are often tried to overcome the infertility problems. Some of these compounds are produced from medicinal plants or their extracts and are increasingly used to protect the sexual organs or treat the hormonal disturbance. In this context, the administration of marjoram to coragentreated rats was functioning in adjusting the plasma levels of sex hormones to a considerable degree. El-Wakf et al. ${ }^{[37]}$ reported a similar increase in the testosterone hormone level by marjoram that could be attributed to the direct effect of marjoram extracts on the hypothalamus-pituitary-testis axis. Furthermore, they demonstrated that marjoram is a rich source of terpenoids, asthymol, carvacrol, $\quad 4$-terpineol, $\gamma$-terpinene, $\alpha$ terpinene. These terpenoids are natural products belonging to the chemical group of terpenes that are the main active constituents of marjoram essential oil and have an obvious role in controlling biosynthesis of the testosterone hormone and hence normalizing the male fertility ${ }^{[37]}$.

In our current study, the coragen +marjoram-treated rats had a significantly higher plasma T3 and T4 levels, as well as a significantly lower plasma TSH and aldosterone levels when compared to coragen-treated group. Ahmed et al. ${ }^{[38]}$ reported a significant increase in thyroid hormones levels (T3 and T4), while a significant decrease in TSH level in obese rats administrated marjoram water extract when compared to obese-control group. They concluded that marjoram extract had a high content of phenolic compounds that are useful for treating obesity accompanied by hyperlipidemia due to their direct effect on lipid metabolism thus improved the thyroid gland activity ${ }^{[38]}$. Moreover, Bina and Rahimi ${ }^{[39]}$ suggested that the marjoram leaves had a significant antioxidant properties and hormonal activity due to their phenolic compounds such as flavonoids (quercetin, kaempferol, catechin, luteolin, and apigenin) and glycosides (kaempferol-3-O-glucoside and quercetin-3O-glucoside).

In the present study, most histopathological alterations induced by coragen were markedly amended by supplementation with marjoram whereas; kidneys and testes histological sections of the rats treated with marjoram showed noticeable development in comparison with the coragen-treated group. Abdelsalam et al. ${ }^{[40]}$ stated that marjoram had a renoprotective activity, since the renal lesions were small and limited to vacuolization of the renal tubular epithelium in rats co-administered adenine with marjoram oil. Marjoram administration reduced the intensity of histopathological changes such as the aggregation of focal inflammatory cells between the renal tubules ${ }^{[40]}$. This enhancement can be linked to marjoram's strong antioxidant activity and high capacity to scavenge ROS, which play an important role in reducing lipid peroxidation and inflammation, and hence tissue injury ${ }^{[40,41]}$. Improvement in the testicular tissue can be related to the active constituents of marjoram, mainly phenolic terpenoids ${ }^{[37]}$. In the herbal or dietary plants, there are numerous bioactive terpenoids that modulate the activity of peroxisome proliferator-activated receptors (PPARs), which are ligand-dependent transcription factors belonging to the nuclear receptors ${ }^{[40]}$. In mammals, there have been identified three subtypes of PPARs, $\alpha, \delta$, and $\gamma$, which are known to play a multitude 
of essential roles in the energy homeostasis and the reproductive function ${ }^{[40]}$.

In conclusion, based on the present data exposure of rats to the sublethal dose ( $2 \mathrm{~g} / \mathrm{kg}$ body weight) of coragen has altered some hematological indices, biochemical parameters, and hormonal profiles, as well as induced histopathological changes in the kidneys and the testes. Subsequently, administration of marjoram ( $5 \mathrm{~g} / \mathrm{kg}$ body weight) induced marked alleviative effects against coragen's harmful consequences. Accordingly, marjoram might be one of the most potent solutions against coragen toxicity as shown in the current experimental study.

\section{COMPLIANCE WITH ETHICAL STANDARDS}

All experimentation, transportation, and care of the animals used in this study were in compliance with the Faculty of Science, Minia University's policy on animal use and ethics. All mandatory laboratory health and safety measures have been adhered with while performing the experimental work of this study.

\section{FUNDING SOURCE DISCLOSURE}

This research received no funds.

\section{CONFLICT OF INTEREST}

The authors declare no conflict of interest.

\section{AUTHORS' CONTRIBUTIONS}

$\mathrm{HFH}$ and NMM designed the research. NMM performed the statistical analysis and drafted the manuscripts. All authors carried out the experiments, as well as revised and approved the manuscript.

\section{REFERENCES}

[1] Hegazy, H. M. R. and Nahas, A. A. (2015). Protective effect of marjoram (Organium majorana L.) against oxidative stress-induced by abamectin. Egy Sci J Pestic, 1: 32-39.

[2] Kumar, A.; Dutta, K.; Najam, A. et al. (2013). Coragen causes haematological alterations in Charles Foster rats. Eur J Toxicol Sci, 2013: 4.

[3] Dutta, K.; Ali, M.; Najam, A. et al. (2014). Ameliorative effect of seed extract of Pterocarpus santalinus on coragen-induced haematological alterations and serum biochemical changes in Charles Foster rats. J Toxicol Environ Health Sci, 6(10): 194-202.

[4] Al-Okbi, S. Y.; Mohamed, D. A.; Hamed, T. E. et al. (2014). Prevention of renal dysfunction by nutraceuticals prepared from oil rich plant foods. Asian Pac J Trop Biomed, 4(8): 618626.

[5] Wang, H.-P.; Liang, Y.-J.; Zhang, Q. et al. (2011). Changes in metabolic profiles of urine from rats following chronic exposure to anticholinesterase pesticides. Pestic Biochem Physiol, 101(3): 232-239.

[6] Hassan, H. F. and Meligi, N. M. (2017). Effects of sublethal abamectin exposure on some hormonal profiles and testicular histopathology in male albino rats and the possible ameliorative role of Eruca sativa. Environ Sci Pollut Res Int, 24(31): 24690-24697.

[7] Refaie, A. A. E.-R.; Ramadan, A. and Mossa, A.-T. H. (2014). Oxidative damage and nephrotoxicity induced by prallethrin in rat and the protective effect of Origanum majorana essential oil. Asian Pac J Trop Med, 7: S506S513.

[8] Mossa, A. T. H. and Nawwar, G. A. M. (2011). Free radical scavenging and antiacetylcholinesterase activities of Origanum majorana L. essential oil. Hum Exp Toxicol, 30(10): 1501-1513.

[9] Ramadan, G.; El-Beih, N. M. and Zahra, M. M. (2012). Egyptian sweet marjoram leaves protect against genotoxicity, immunosuppression and other complications induced by cyclophosphamide in albino rats. $\mathrm{Br} \mathrm{J}$ Nutr, 108: 1059-1068. 
[10] Ramadan, G.; El-Beih, N. M.; Arafa, N. M. S. et al. (2013). Preventive effects of Egyptian sweet marjoram (Origanum majorana L.) leaves on haematological changes and cardiotoxicity in isoproterenol-treated albino rats. Cardiovasc Toxicol, 13: 100-109.

[11] Desouky, S.; Marzouk, M.; Soliman, A. M. et al. (2015). Modulatory effect of Origanum majorana extract against cisplatin-induced dyslipidemia in rats. IJCRLS, 4(6): 228-234.

[12] Prerna and Vasudeva, N. (2015). Organum majorana L.-phyto-pharmacological review. IJNPR, 6(4): 261267.

[13] Meligi, N. M.; Hassan, H. F. and Honyda, S.M. (2019). Coragen induced toxicity and the ameliorative effect of an Origanum majorana L. in male albino rats. JAS, 15(9): 33-44.

[14] Ismail, A. A. A.; Astley, P.; Burr, W. A. et al. (1986). The role of testosterone measurement in the investigation of androgen disorders. Ann Clin Biochem, 23: 113-134.

[15] McCann, D. S. and Kirkish, L. S. (1985). Evaluation of free testosterone in serum. J Clin Immunoassay, 8: 234236.

[16] Burtis, C. A. and Ashwood, E. R. (1994). Tietz Textbook of Clinical Chemistry, $2^{\text {nd }}$ edition. W B Saunders Company, Philadelphia.

[17] Witherspoon, L. R. and Shuler, S. E. (1984). Estimation of free thyroxine concentration: clinical methods and pitfalls. J Clin Immunoassy, 7: 192205.

[18] Felig, P.; Baxter, J. D.; Broadus, A. E. et al. (1987). Endocrinology and Metabolism, $2^{\text {nd }}$ edition. McGraw-Hill, New York, NY, USA.

[19] Hay, I. D. and Klee, G. G. (1993). Linking medical needs and performance goals: clinical and laboratory perspectives on thyroid disease. Clin Chem, 39(7): 1519-1524.
[20] Cartledge, S. and Lawson, N. (2000). Aldosterone and renin measurements. Ann Clin Biochem, 37: 262-278.

[21] Kanu, K. C.; Ijioma, S. N. and Atiata, O. (2016). Haematological, biochemical and antioxidant changes in Wistar rats exposed to dichlorvos based insecticide formulation used in southeast Nigeria. Toxics, 4 (4): 28 (DOI: 10.3390/toxics4040028).

[22] Eissa, F. I. and Zidan, N. A. (2010). Haematological, biochemical and histopathological alterations induced by abamectin and Bacillus thuringiensis in male albino rats. Acta Biol Hung, 61: 33-44.

[23] Fattahi, E.; Parivar, K.; Jorsaraei, S. G. A. et al. (2009). The effects of diazinon on testosterone, FSH and LH levels and testicular tissue in mice. Iran J Reprod Med, 7(2): 59-64.

[24] El-Kashoury, A. A.; Salama, A. F.; Selim, A. I. et al. (2010). Chronic exposure of dicofol promotes reproductive toxicity in male rats. Life Sci, 7(3): 5-19.

[25] Ghosh, C. and Medda, J. N. (1999). Ameliorating effects of thyroxine and atropine in phosphamidon intoxicated chick embryos. Biomed Environ Sci, 12: 34-42.

[26] Abou El-Magd, S. A.; Sabik, L. M. E. and Shoukry, A. (2011). Pyrethroid toxic effects on some hormonal profile and biochemical markers among workers in pyrethroid insecticides company. Life Sci, 8: 311-322.

[27] Lamberts, S. W.; Zuyderwijk, J.; Den Holder, F. et al. (1989). Studied on the conditions determining the inhibitory effect of somatostatin on adrenocorticotropin, prolactin and thyrotropin release by cultured rat pituitary cells. Neuroendocrinology, 50: 44-50.

[28] Ponda, M. P. and Hostetter, T. H. (2006). Aldosterone antagonism in chronic kidney disease. CJASN, 1(4): 668-677. 
[29] Meligi, N. M. and Hassan, H. F. (2017). Protective effects of Eruca sativa (rocket) on abamectin insecticide toxicity in male albino rats. Environ Sci Pollut Res Int, 24(10): 9702-9712.

[30] Rekha; Raina, S. and Hamid, S. (2013). Histopathological effects of pesticide-cholopyrifos on kidney in albino rats. J Int Res Med Sci, 1(4): 465-475.

[31] Debnath, D. and Mandal, T. K. (2000). Study of quinalphos (an environmental oestrogenic insecticide) formulation (Ekalux 25 E.C.)-induced damage of the testicular tissues and antioxidant defence systems in Sprague-Dawley albino rats. J Appl Toxicol, 20(3): 197 204.

[32] Sheweita, S. A.; Tilmisany, A. M. and Al-Sawaf, H. (2005). Mechanisms of male infertility: role of antioxidants. Curr Drug Metab, 6(5): 495501.

[33] Nose, K. (2000). Role of reactive oxygen species in the regulation of physiological functions. Biol Pharm Bull, 23(8): 897-903.

[34] Latchoumycandane, C. and Mathur, P. P. (2002). Induction of oxidative stress in the rat testis after shortterm exposure to the organochlorine pesticide methoxychlor. Arch Toxicol, 76(12): 692-698.

[35] Babazadeh, M. and Najafi, G. (2017). Effect of chlorpyrifos on sperm characteristics and testicular tissue changes in adult male rats. Vet Res Forum, 8(4): 319-326.

[36] Shati, A. A. (2011). Effects of Origanum majorana L. on cadmium induced hepatotoxicity and nephron- toxicity in albino rats. Saudi Med J, 32(8): 797-805.

[37] El-Wakf, A. M.; Elhabibi, E. M. and Abd El-Ghany, E. (2015). Preventing male infertility by marjoram and sage essential oils through modulating testicular lipid accumulation and androgens biosynthesis disruption in a rat model of dietary obesity Egypt $\mathbf{J}$ basic appl sci, 2(3): 167-175.

[38] Ahmed, L. A.; Ramadan, R. S. and Mohamed, R. A. (2009). Biochemical and histopathological studies on the water extracts of marjoram and chicory herbs and their mixture in obese rats. Pak J Nutr, 8(10): 15811587.

[39] Bina, F. and Rahimi, R. (2017). Sweet marjoram: a review of ethnopharmacology, phytochemistry, and biological activities. J Evid Based Complementary Altern Med, 22: 175185.

[40] Abdelsalam, H. M.; Diab, A. A.; Zahra, M. H.; et al. (2019). Therapeutic effects of Origanum majorana and propolis against nephrotoxicity induced by adenine. Biol Eng Med, 4: 1-9.

[41] Hassanen, N. (2012). Hepatoprotective effects of marjoram (Origanum marjorana L.) on oxidative stress against carbon-tetrachloride-induced toxicity in rats. J Egypt Nutr Health, 7(1): 69-86.

[42] Goto, T.; Takahashi, N.; Hirai, S. et al. (2010). Various terpenoids derived from herbal and dietary plants function as PPAR modulators and regulate carbohydrate and lipid metabolism. PPAR Res, 2010: 483958 (DOI: $10.1155 / 2010 / 483958)$.

\section{How to cite this article:}

Hassan, H. F.; Mohammed, H. S. and Meligi, N. M. (2021). Potential impact of marjoram on corageninduced physiological and histological alterations in male albino rats. Egyptian Journal of Zoology, 75: 25-38 (DOI: 10.12816/ejz.2020.49316.1044). 


\title{
التأثير المحتمل للبردقوش على التغيرات الفيزيولوجية والهيستولوجية المُستحثة بالكوراجين في ذكور الجرذان الفيران المهقاء
}

\author{
هناء فوزي حسن، هنيا صافى محمد، نهي محمد مليجي \\ قسم علم الحيوان، كلية العلوم، جامعة المنيا، المنيا، جمهورية مصر العربية
}

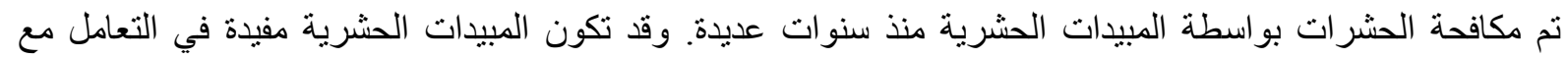

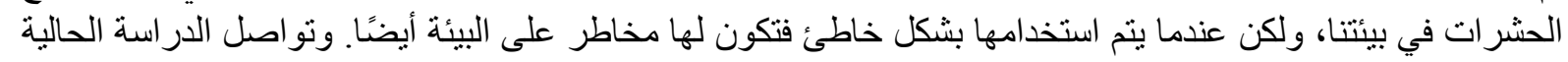
تقييم التأثير ات المخفقة المحتملة للبردقوش (Origanum majorana L.

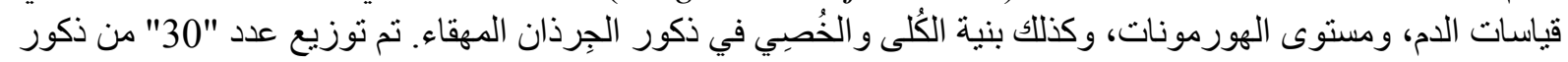

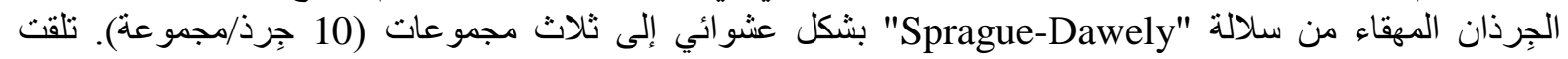

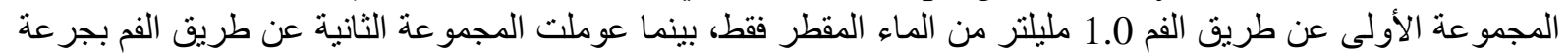

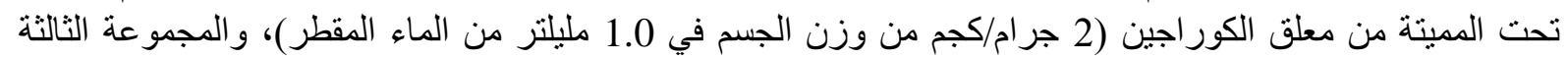

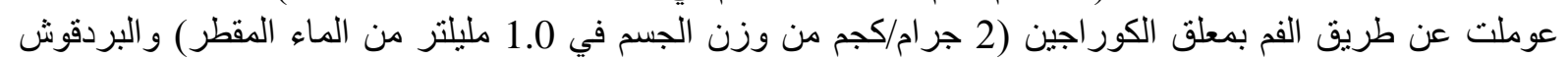

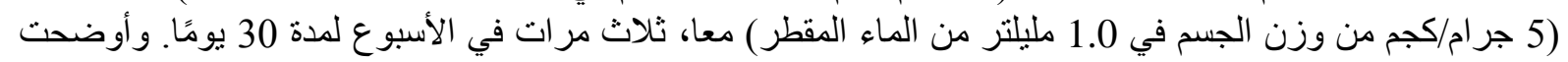
النتائج أن البردقوش خفف تخفيفا ملحوظا إحصائبا (P>0.05) فقر الدياء

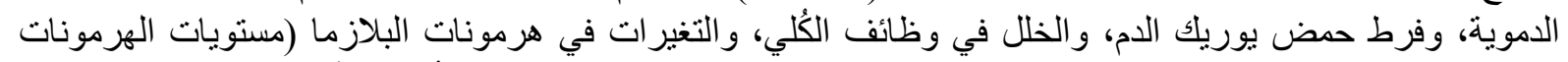

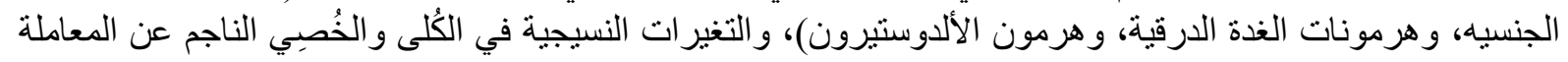

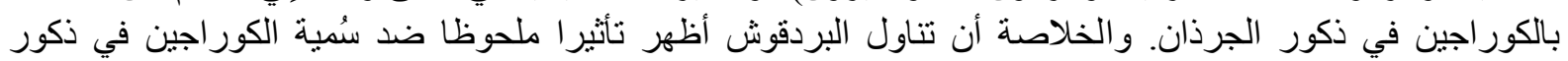
الجِرذان. 